\title{
Relationship between functional levels and movement in tetraplegic patients. A retrospective study
}

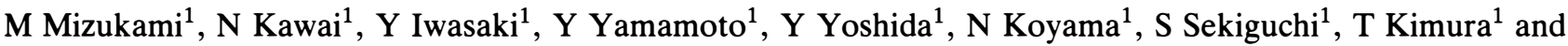 \\ R Nihei ${ }^{2}$ \\ Departments of ${ }^{1}$ Physical Training, ${ }^{2}$ Orthopedics, National Rehabilitation Center for the Disabled Hospital, 4-1 \\ Namiki, Tokorozawa, Saitama Prefecture 359 Japan
}

\begin{abstract}
The aim of the present study was to set targets for each spinal lesion level after determining the relationship between the spinal lesion level and movement abilities in patients with tetraplegia following injury to the cervical cord. A total of 109 patients, 96 men and 13 women were included in the study. We mainly examined locomotion and transfer capabilities according to Zancolli's classification. The results of this study showed that $50 \%$ of the patients classified as $\mathrm{C6}_{\mathrm{A}}, 75 \%$ of $\mathrm{C6}_{\mathrm{B} 1}$ and $96 \%$ of the patients classified $\mathrm{C}_{\mathrm{B} 2}$ accomplished bed transfer. The number of patients who could manage toilet transfer was $53 \%$ in the group classified as $C 6_{\mathrm{B} 1}$ and $85 \%$ in group $\mathrm{C} 6_{\mathrm{B} 2}$. These results suggest that achievement of those classified as $\mathrm{C}_{\mathrm{B} 2}$ is a clue to the assumption that the patient will achieve toilet transfer capability and can perform ADL independently.
\end{abstract}

Keywords: activities of daily living; Zancolli classification; goal setting; tetraplegia; rehabilitation

\section{Introduction}

The incidence of cervical cord injuries tends to increase in association with the changes in our social and industrial activities. Differing from injuries of the thoracic and the lumbar cord, residual functions vary largely at each level in those with the cervical cord injuries. Accordingly, the finally reached functional level also varies widely. Several reports deal with the relationship between the spinal lesions level and the abilities that are finally obtained. ${ }^{1,2}$ However, these reports deal only with one spinal segment. But residual function varies widely even among those with injuries involving one spinal segment; these differences being particularly marked at C6 level. Zancolli in $1979^{3}$ published a detailed subclassification method based on an evaluation of the residual functions of the upper extremities and to classify these differences for one spinal segment (Table 1).

In the present study we followed Zancolli's classification to explain the relationship between functional levels and locomotion and transfer capabilities in patients with tetraplegia. To set goals for each level we examined a total of 109 patients with complete tetraplegia regarding the ratio of locomotion and the ability to transfer.

In the main we will discuss the results and prediction of a borderline situation determining whether independence in activities of daily living (ADL) will be

Table 1 Zancolli's Classification

\begin{tabular}{|c|c|c|}
\hline C5 & $\begin{array}{l}\text { A } \\
\text { B }\end{array}$ & $\begin{array}{l}\text { Without brachioradialis } \\
\text { With brachioradialis }\end{array}$ \\
\hline C6 & $\begin{array}{l}\text { A } \\
\text { B }\end{array}$ & $\begin{array}{l}1 \text { Without pronator teres and flexor carpi radialis } \\
2 \text { With pronator teres and without flexor carpi radialis } \\
3 \text { With pronator teres, flexor carpi radialis and triceps }\end{array}$ \\
\hline C7 & $\begin{array}{l}\text { A } \\
\text { B }\end{array}$ & $\begin{array}{l}\text { Complete extension of ulnar fingers and paralysis of radial fingers and thumb } \\
\text { Complete extension of all fingers and weak thumb extension }\end{array}$ \\
\hline $\mathrm{C} 8$ & $\begin{array}{l}\text { A } \\
\text { B }\end{array}$ & $\begin{array}{l}\text { Complete flexion of ulnar fingers and paralysis of flexion of radial fingers and thumb. Complete thumb extension } \\
\text { Complete flexion of all fingers and weak thumb flexion. Weak thenar muscles. Paralysis of the intrinsic } \\
\text { muscles of the fingers without or with flexor superficialis }\end{array}$ \\
\hline
\end{tabular}


reached by patients with a $\mathrm{C} 6$ level lesion, the most frequent site of injury causing tetraplegia. These patients also have the greatest residual functions. Finally we will add some personal opinions regarding the method of rising up, moving or transferring of such patients.

\section{Patients and methods}

A total of 109 patients, 96 men and 13 women, with traumatic tetraplegia (Frankel classification A and B) who from 1980 until June 1991 completed a course of physical training at the National Rehabilitation Center for the Disabled Hospital were included in our study. The patients ages ranged from 14 to 61 years and the average age was 28.2 years $( \pm 10.59$ years $)$. At the beginning of the physical therapy a period of $1-112$ months, average $16.8( \pm 19.93)$ months, had passed since the time of their injury. Duration of the physical therapy ranged from 2 to 23.5 months, average 9.4 months $( \pm 5.40)$. Classified by functional level, four patients had $\mathrm{C} 4,15$ had $\mathrm{C} 5,55$ had $\mathrm{C} 6,13$ had $\mathrm{C} 7$ and nine had C8 (Table 2). Spinal lesions levels were classified according to Zancolli's classification using 10 subcategories for levels $\mathrm{C} 5$ through to $\mathrm{C} 8$, so that together with $\mathrm{C} 4$ level lesions there was a total of eleven stages. Left and right side were evaluated separately. We then used the higher level of either left or right to analyse the results.

The 10 items for an evaluation of sitting up, moving and of transfer capabilities were:

- Operation of an electric wheelchair

- Operating of a manual wheelchair

- Turning over on bed

- Sitting up on bed

- Transfer between wheelchair and bed

- Transfer between wheelchair and toilet

- Transfer between wheelchair and car seat

- Loading wheelchair into car

- Transfer to bed, with a lateral approach

- Transfer from floor to wheelchair

The above items were evaluated according to the following four standard criteria:

$0=$ no experience, impossible, requires assistance

$1=$ requires partial assistance

2 = standing, conditional, use of supportive devices, required time

$3=$ independence.
When criteria reached level 2 or 3 during the evaluation the accomplishment was evaluated and the locomotion achievement ratio was calculated.

We considered age, time of start of the PT treatment and duration from injury until the beginning of training to be factors influencing the locomotion achievement ratio and we also examined their relation.

\section{Results}

Table 3 shows the locomotion achievement ratios for each functional level and each evaluation item when patients were discharged. All results of the $\chi^{2}$ test showed on the $5 \%$ significance level or $0.1 \%$ significant differences. Below we will outline the results for each movement.

\section{Operating a wheelchair}

Operating a wheelchair is impossible for patients with a C4 lesion. Here an electric wheelchair has to be used. Approximately 12 patients $(60 \%)$ who were classified as $C 5_{A} C 5_{B}$ could operate a manual wheelchair.

\section{Movements on the bed}

For three patients $(23 \%)$ who were classified as $\mathrm{C}_{\mathrm{B}}$ and one patient $(50 \%)$ classified as $\mathrm{C}_{\mathrm{A}}$ turning over on the bed became possible. Sitting up on the bed became possible for one patient $(8 \%)$ classified as $C 5_{B}$, for one $(50 \%)$ classified as $\mathrm{C6}_{\mathrm{A}}$ and for 15 patients $(88 \%)$ classified as $\mathrm{C6}_{\mathrm{B} 1}$. Patients used the bedrails, straps or similar helps for those movements. Even some patients with a C5 level lesion could perform these movements. However, patients with high cervical lesions often showed a marked spasticity of the muscles of the upper extremities, in particular of the biceps brachii muscles. Thus in most of these cases this type of movement is not possible.

\section{Bed-wheelchair transfer}

This movement is one of the decisive ones in the process of gaining ADL independence. Bed-wheelchair transfer by an anterior approach was for patients classified above C5 $0 \%$, for patients classified as $\mathrm{C6}_{\mathrm{A}}$ one patient $(50 \%)$, for level $\mathrm{C} 6_{\mathrm{B} 1} 12$ patients $(71 \%)$, for level $\mathrm{C}_{\mathrm{B} 2} 25$ patients (96\%) and below $\mathrm{C} 6_{\mathrm{B} 3} 100 \%$.

Table 2 Characteristics of patients

\begin{tabular}{|c|c|c|c|c|}
\hline & $\begin{array}{l}\text { Number } \\
\text { of cases }\end{array}$ & $\begin{array}{l}\text { Mean age } \\
\text { (years) }\end{array}$ & $\begin{array}{l}\text { Duration of the } \\
\text { injury (months) }\end{array}$ & $\begin{array}{l}\text { Duration of } P T \\
\text { training (months) }\end{array}$ \\
\hline $\mathrm{C} 4$ & 5 & $34.4( \pm 9.54)$ & $12.9( \pm 9.35)$ & $7.6( \pm 2.58)$ \\
\hline $\mathrm{C} 5$ & 18 & $23.4( \pm 7.87)$ & $10.6( \pm 6.15)$ & $10.0( \pm 5.01)$ \\
\hline C6 & 61 & $28.6( \pm 11.46)$ & $20.5( \pm 24.65)$ & $10.3( \pm 5.55)$ \\
\hline $\mathrm{C7}$ & 15 & $30.9( \pm 8.06)$ & $15.3( \pm 11.98)$ & $7.8( \pm 5.72)$ \\
\hline C8 & 10 & $27.4( \pm 9.64)$ & $8.2( \pm 5.22)$ & $5.8( \pm 3.03)$ \\
\hline Mean & & $28.2( \pm 10.59)$ & $16.8( \pm 19.93)$ & $9.4( \pm 5.40)$ \\
\hline
\end{tabular}




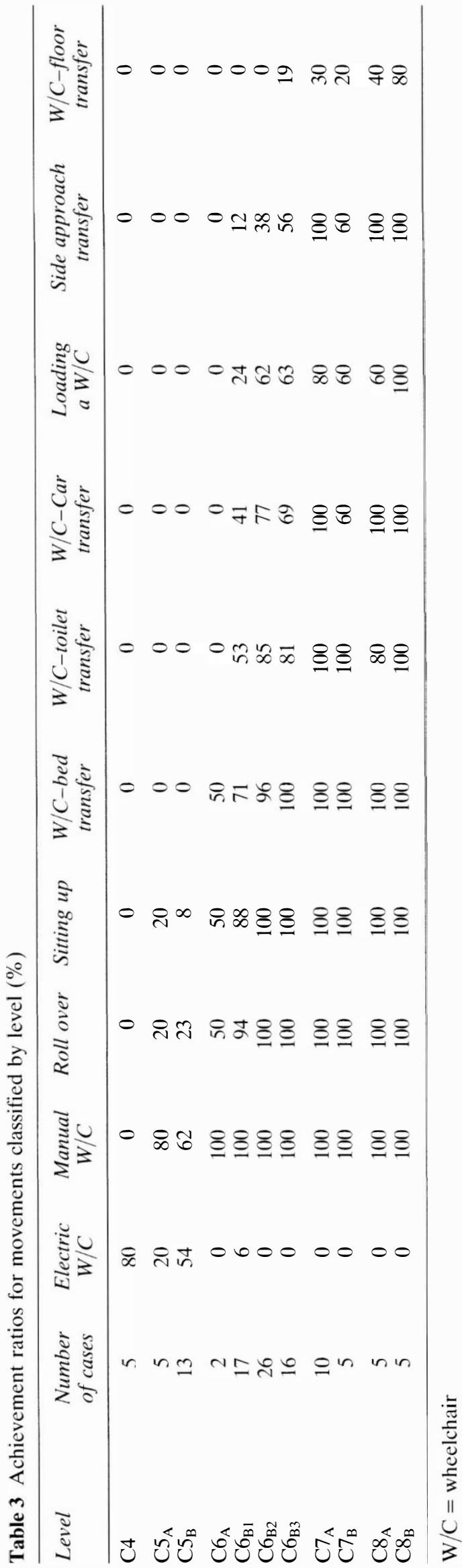

Toilet-wheelchair transfer

Toilet-wheelchair transfer was possible for $0 \%$ of the patients classified as having a $\mathrm{C6}_{\mathrm{A}}$ lesion; for level $\mathrm{C} 6_{\mathrm{B} 1}$ nine patients $(53 \%)$, for level $\mathrm{C}_{\mathrm{B} 2} 22$ patients $(85 \%)$ and even for level $\mathrm{C}_{\mathrm{B} 3} 13$ patients $(81 \%)$. For levels below $\mathrm{C}_{\mathrm{B} 2}$ the anterior approach was mainly used, but later we will explain that this movement requires excellent balance in the sitting position and a powerful push-up ability. Thus, for patients who cannot master this movement or patients classified as $\mathrm{C6}_{\mathrm{B} 1}$ a Japanese style toilet built into a flat table was used (Figure 1).

Transfer to a wheelchair and loading a wheelchair into a car

Regarding the extension of the range of action in daily life of patients with tetraplegia it is vital that the patient can drive a car. But usually transfer to and loading a wheelchair into a car is more difficult than the actual car driving. In the present study we found that both transfer and loading were impossible for patients classified as $\mathrm{C6}_{\mathrm{A}}$ or higher. For patients classified as $\mathrm{C}_{\mathrm{B} 1}$ transfer was possible in seven patients $(41.1 \%)$, and loading of the wheelchair in four patients $(24 \%)$; for level $\mathrm{C}_{\mathrm{B} 2}$ the respective values were 20 patients $(77 \%)$ and 16 patients $(62 \%)$ and for level $\mathrm{C}_{\mathrm{B} 3} 11$ patients $(69 \%)$ and 10 patients $(63 \%)$. For patients classified as $\mathrm{C7}_{\mathrm{A}}$ transfer was possible $100 \%$ and loading of a wheelchair was $80 \%$; even for patients classified as $\mathrm{C7}_{\mathrm{B}}$ these movements proved to be difficult and their respective values fell to $60 \%$.

\section{Transfer by a lateral approach and transfer from the floor to a wheelchair}

In the previous sections we described the basic pattern of transfer for patients with tetraplegia as being the anterior approach. Patients who have mastered this technique have gained a very high level of movement

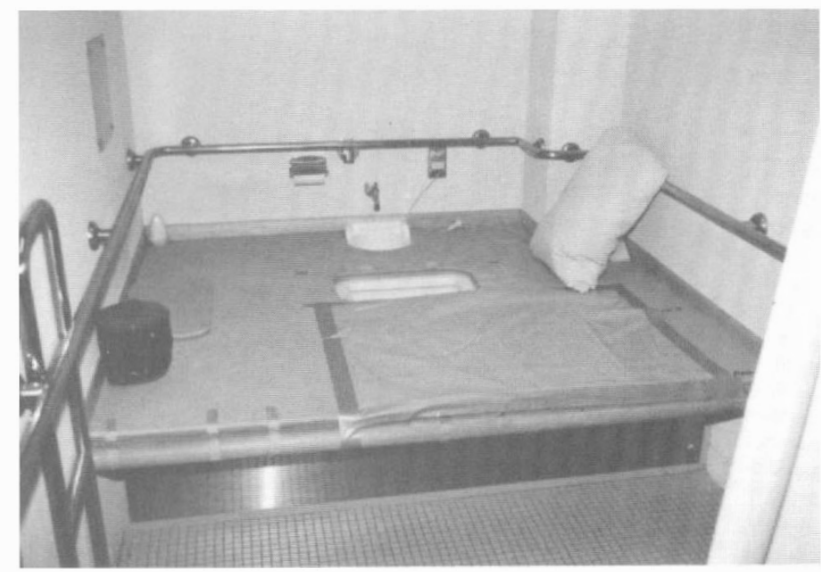

Figure 1 Japanese style toilet built into a flat table. The tetraplegic patient can sit on the bowl in an extended sitting position. The height of the table is almost equal to that of the wheelchair, so that the transfer from wheelchair to toilet bowl is easy. This is particularly useful for patients who cannot easily push up from the wheelchair sitting position 
and some can accomplish the transfer by the lateral approach swiftly and without much energy being required. This method is used mainly for transfer between bed and wheelchair. The percentage of patients successfully mastering this movement was: above level $\mathrm{C6}_{\mathrm{A}} 0 \%$, for level $\mathrm{C6}_{\mathrm{B} 1}$ two patients $(12 \%)$, for level $\mathrm{C}_{\mathrm{B} 2} 10$ patients $(38 \%)$ and for level $\mathrm{C}_{\mathrm{B} 3}$ nine patients $(56 \%)$. Even while this ratio was for patients classified as $\mathrm{C} 7_{\mathrm{B}}$ or lower and for $\mathrm{C} 7_{\mathrm{A}}, \mathrm{C} 8_{\mathrm{A}}, \mathrm{C} 8_{\mathrm{B}}$ was $100 \%$, it varied widely and for level $C 7_{B}$ was only $60 \%$. This means individual differences manifest themselves during training to develop a highly balance demanding push-up from the sitting position. The ratio of vertical transfer between floor and wheelchair was: above level $\mathrm{C6}_{\mathrm{B} 2} 0 \%$, for level $\mathrm{C}_{\mathrm{B} 3}$ three patients $(19 \%)$, for level $C 7_{A}$ three patients $(30 \%)$, for $C 7_{B}$ one patient $(20 \%)$, for $\mathrm{C} 8$ A two patients $(40 \%)$ and for $\mathrm{C} 8$ four patients $(80 \%)$. This movement depends on the ability to push up.

Influences on the degree of successfully mastering movements of factors other than functional levels are also important. We examined two aspects, under 30 years and a post-traumatic course of less than 12 months before the beginning of training, regarding their influence on functional levels and relative importance. Table 4 shows the ratios of successful mastering of each movement classified for levels $\mathrm{C6}_{\mathrm{B} 1}, \mathrm{C} 6_{\mathrm{B} 2}, \mathrm{C} 6_{\mathrm{B} 3}$ and each condition as well as the risk ratio (for a confidence interval of $95 \%$ ). For the condition 'age less than 30 years' the $\chi^{2}$ test yielded significantly better results $(P<0.05)$ : bed transfer for level $\mathrm{C6}_{\mathrm{B} 1}(85 \%)$, toilet transfer for level $\mathrm{C} 6_{\mathrm{B} 1}$ and $\mathrm{C} 6_{\mathrm{B} 2}(69 \%$ and $100 \%)$, transfer to a car $(54 \%$ and $89 \%)$, transfer from floor to wheelchair for level $\mathrm{C6}_{\mathrm{B} 3}(43 \%)$. The risk ratio for these items also showed high values. For the condition 'post-traumatic course of less than 12 months' we did not find any significantly different results.

\section{Discussion}

The results of the present study revealed a tendency of the upper limits of possible movements to exceed those formerly reported limits. Below we will discuss the setting and execution of the target movement for each functional level individually.

C5

Target movement for patients classified as C5 is probably operating a wheelchair. Some reports say the use of electric wheelchairs is the rule (especially for C $\left.5_{\mathrm{A}}\right)^{2,4}$ However, the results of the present study revealed that operating a wheelchair is possible in the majority of patients, clearly indicating the target movement even for patients classified as $\mathrm{C} 5_{\mathrm{A}}$. Recent developments of wheelchairs are in many aspects responsible for this improvement. The use of aluminum alloys for the frame makes wheelchairs lighter, the use of thin tyres for bicycle racing (pneumatic tubeless tyres) reduces surface resistance, hand rims have knobs attached and vinyl coatings matching rubber gloves are

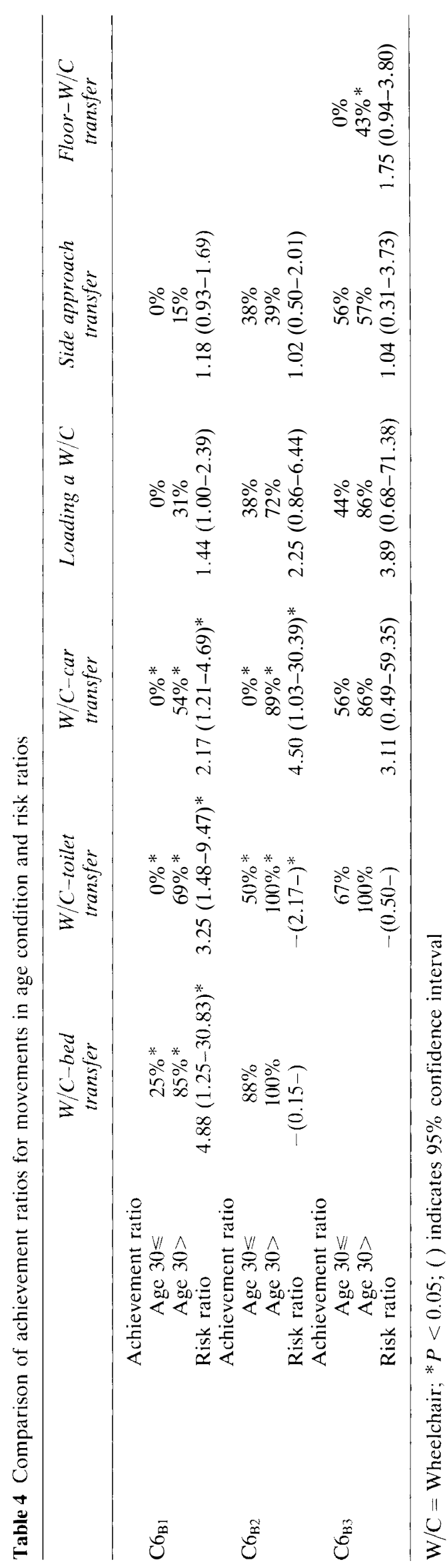


also provided. Improvement of the interior environment in the form of the removal of steps and the installation of supportive equipment has also had an influence. Yet approximately $40 \%$ of such patients cannot manage to drive a wheelchair and are either assisted or use an electric wheelchair. Serious spasticity, mainly of the upper limbs, limits movement for most of these patients. Turning over in bed becomes possible for $25 \%$ of the patients classified as $\mathrm{C}_{\mathrm{B}}$ patients, but only approximately $8 \%$ succeed in sitting up. Bedrails, straps and other means should be used during training, provided that there is no spasticity of the upper limbs and no inhibiting factors. Mastering this movement would relieve the burden on the helper for posture changing during the night.

\section{C6}

Zancolli's classification also uses a division into four stages, which include a very wide range of functional levels. Some reports deal with the movements to be mastered at these levels, such as turning over in the bed, sitting up, partially assisted transfer to a wheelchair ${ }^{2}$ or becoming independent in the transfer between wheelchair and bed. ${ }^{5-7}$

Even in the majority of patients classified as $\mathrm{C6}_{\mathrm{A}}$, in whom the extensor carpi radialis muscles (below ECR) do not function effectively, turning over and sitting up as well as transfer between bed and wheelchair is possible, so that training should be tried. Turning over and getting up for almost all of these patients is possible with a level of $\mathrm{C} 6_{\mathrm{B} 1}$, where ECR start functioning. The transfer between bed and wheelchair becomes possible in approximately $70 \%$. Mastering this movement is highly possible. For these two classes function of the subclavian part of the pectoralis major muscle is also insufficient, so that the biceps brachii muscle is used as a substitute during turning over and rising up with the help of bedrails or straps. Transfer between wheelchair and bed was achieved by the anterior approach.

Transfer to a toilet and the use of ordinary toilet stools are also difficult when the patient's sitting balance on the chair is poor or an efficient push-up is not possible. However, some patients can manage a toilet using a Japanese style bowl built into a flat table (Figure 1). When balance in the sitting position and lower limb control are good (eg as long as transfer is not made impossible by poor balance or strong spasticity of the hip adductors that prevents lifting the legs into the car), transfer to a car using a sliding board can also be possible.

For those with a lesion at level $\mathrm{C}_{\mathrm{B} 2}$ an effective push-up becomes possible, and this is very advantageous for all forms of transfer, including transfer between bed and wheelchair, onto a toilet and into a car. Additionally, loading a wheelchair into a car and lateral transfer should also be tried.

According to reports examining the ratio of achievement of movements $61 \%$ of 66 patients with residual ECR function and triceps muscle power of less than 2 (corresponding to Zancolli's classification $C 6_{\mathrm{B} 1}$ and $\left.\mathrm{C}_{\mathrm{B} 2}\right)$ achieved bed transfer. The ratio of patients also acquiring the capability of transfer to a car or a toilet was $6 \% .{ }^{1}$ Our study included 37 patients with lesions at the same level, but the achievement ratio for the same movements was $85 \%$ and $62 \%$ respectively, exceeding the figures from reports in the literature to date.

Superiority or inferiority of the movements on this level largely depends on push-up power (also including balance). Transfer to a toilet, in particular, requires a push-up from a sitting position as well as forward and backward propulsion from that position. Forward propulsion can be accomplished by shifting the body weight forward by flexing the thoracic and lumbar spine while the hip is free. Loss of balance in a forward direction can be overcome by the placement of a cushion. This is comparatively easy, because the weight shift movement has the same direction as the beginning of the push-up.

In contrast, backward movement requires a highly advanced technique to stop when the push-up forward cause the buttocks to be lifted out of the chair. Additionally, the latissimus dorsi muscles are used to lift the pelvis while protracting the shoulder girdle. This moves the body backwards. Thus good balance during the lifting of the buttocks is essential. The push-up power is said to reach the upper limit of a practical applicability approximately for those at $\mathrm{C} 6$ level $^{6,8}$ or C7. ${ }^{9}$ We set it at $\mathrm{C}_{\mathrm{B} 2}$.

The triceps brachii muscle begins to function and the deltoid muscle also contributes effectively to control balance during push-up once level $\mathrm{C}_{\mathrm{B} 3}$ is reached. Thus, transfer in the push-up posture becomes much easier. Improvement of motility in the sitting position should lead the patient to try the lateral approach for transfer.

The movement for lifting the lower limbs also becomes much easier when the flexor carpi radialis (below FCR) begin to function. This increases the possibility of loading a wheelchair into a car. Transfer from the floor to a wheelchair is still somewhat difficult. However, when conditions such as the length of the upper limbs, flexibility of the spine and adequate tension of the trunk muscles are met, realisation of this movement can be possible, since the function of the pectoralis major muscle contributes to the push-up.

\section{C7-C8}

Below the level of $\mathrm{C} 7$ almost all muscles, except those of the hand and the fingers, function nearly normally. Thus, most movements should be possible without any problems. The form of transfer also shifts generally from the anterior approach to the more practical form of the lateral approach. However, because of the above outlined reasons transfer from the floor is still difficult for many of these patients.

Above we described the results of our study based on Zancolli's classification and the movements possible at each level. We have already stated that the capabilities of locomotion determine the functional level of patients with tetraplegia. Although these are essential conditions, they are not sufficient. We must also consider the 
influence of other factors. In the present study we confirmed the influence of age on certain movements, but we could not confirm any influence of the interval from injury until the beginning of the rehabilitation. Besides the functional level the following factors are considered to relate to the mastering of movements. ${ }^{10-19}$

First, a history of sports, therapeutic and rehabilitation environment. Physical factors include flexibility of various joints, including the spine, spasticity, arm length, sitting height, body weight and muscle power of the residual functional muscles. Internal factors include physical fitness, complications, susceptibility to psychological disorders and motivation. Taking these factors into account all possible movements should be actively tried. Time should not be wasted in the training for difficult movements, but the introduction of appropriate devices and environmental adjustments should be actively considered.

\section{References}

1 Bromley I. Tetraplegia and Paraplegia. 3rd Japanese edn. Tokyo: Igaku Shoin, 1978, pp 20-26.

2 Yabe Y. Reconstructive surgery for the quadriplegic hand. Sogo Rehabil 1974; 2: 536-543.

3 Zancolli E. Structural and Dynamic Basis of Hand Surgery. 2nd edn. Lippincott: Philadelphia, 1979.

4 Kanematsu $\mathrm{H}$ et al. Potential in activities of daily living of spinal cord lesions. Sogo Rehabil 1976; 4: 793-799.
5 Fukushima T. Training of postural and bed activities for quadriplegic patients at home. Rigaku ryoho to Sagyo Ryoho 1982; 6: 41-50.

6 Nakayama A. Transfer ability of quadriplegic patients. Rigaku ryoho to Sagyo Ryoho 1982; 16: 303-309.

7 Shino T. Bed mobility and transfer in quadriplegia. Rigaku ryoho janaru 1990; 24: 453-457.

8 Shimoda $\mathrm{H}$, Onoda $\mathrm{H}$. Programming of physical therapy 4: Physical therapy program for spinal cord injury. Rigaku ryoho janaru 1990; 24: 243-248.

9 Ando $\mathrm{N}$ et al. Some considerations and kinesiological analyses of push-up motion in patients with quadriplegia. Sogo Rehabil 1979; 7: 657-663.

10 Hashimoto T. Physical therapy for quadriplegia. Sogo Rehabil 1974; 2: 47-53.

11 Hakata S, Doi T. Follow-up study on patients with cervical cord injury. Sogo Rehabil 1979; 7: 671-675.

12 Joan CR. Traumatic quadriplegia, follow-up study of self-care skill. Arch Phys Med Rehabil 1980; 61: 316-321.

13 Ando N. ADL tests for quadriplegia. Sogo Rehabil 1982; 10: 1033-1037.

14 Mizukami M et al. Sitting balance of paraplegic patients. Nat Rehabil Res Bull Jpn 1984; 5: 27-34.

15 Kikuya $\mathrm{O}$ et al. Biomechanical analysis of push-up motion in patients with spinal cord injury. Rigaku ryoho to Sagyo Ryoho 1987; 21: 162-168.

16 Yarkony GM et al. Rehabilitation outcomes in C5 quadriplegia. Am J Phys Med Rehabil 1988; 73-76.

17 Yarkony GM et al. Rehabilitation outcomes in C6 quadriplegia. Paraplegia 26: 177-185.

18 Ford JR, Duckworth B. Physical Management for the Quadriplegic Patient. 2nd Japanese edn. Tokyo: Ishiyaku Publishers, 1990, pp. 615-631.

19 Mizukami M. Practice of ADL training 1: Sitting-up and transfer exercises in quadriplegics. Rigaku ryoho janaru 1991; 25: 485-491. 